Published in final edited form as:

Curr Top Microbiol Immunol. 2009 ; 330: 213-241.

\title{
Measles virus for cancer therapy
}

\author{
Stephen J. Russell, M.D., Ph.D. and
}

Mayo Clinic Department of Molecular Medicine, $2001^{\text {st }}$ Street SW, Rochester, MN 55905, Phone: 507-824-8384, Fax: 507-284-8388, sjr@mayo.edu

\section{Kah Whye Peng, Ph.D.}

Mayo Clinic Department of Molecular Medicine, $2001^{\text {st }}$ Street SW, Rochester, MN 55905, Phone: 507-824-8357, Fax: 507-284-8388, peng.kah@mayo.edu

\begin{abstract}
Measles virus offers an ideal platform from which to build a new generation of safe, effective oncolytic viruses. Occasional "spontaneous" tumor regressions have occurred during natural measles infections, but common tumors do not express SLAM, the wild-type MV receptor, and are therefore not susceptible to the virus. Serendipitously, attenuated vaccine strains of measles virus have adapted to use CD46, a regulator of complement activation that is expressed in higher abundance on human tumor cells than on their non transformed counterparts. For this reason, attenuated measles viruses are potent and selective oncolytic agents showing impressive antitumor activity in mouse xenograft models. The viruses can be engineered to enhance their tumor specificity, increase their antitumor potency and facilitate noninvasive in vivo monitoring of their spread. A major impediment to the successful deployment of oncolytic measles viruses as anticancer agents is the high prevalence of pre-existing anti measles immunity, which impedes bloodstream delivery and curtails intratumoral virus spread. It is hoped that these problems can be addressed by delivering the virus inside measles-infected cell carriers and/or by concomitant administration of immunosuppressive drugs. From a safety perspective, population immunity provides an excellent defense against measles spread from patient to carers and, in fifty years of human experience, reversion of attenuated measles to a wild type pathogenic phenotype has not been observed. Clinical trials testing oncolytic measles viruses as an experimental cancer therapy are currently underway.
\end{abstract}

\section{Oncolytic Viruses}

Viruses that replicate selectively in neoplastic tissues (oncolytic viruses) hold considerable promise as novel therapeutic agents for the treatment of human malignancies and many such agents are currently under investigation, both in preclinical studies and in human clinical trials.[1-4] The existence of viruses was not recognized until the turn of the $19^{\text {th }}$ century, but ever since that time, they have continued to attract considerable interest as possible agents of tumor destruction.[5, 6] Clinical observations suggested that, given the right set of conditions, cancers would sometimes regress during naturally acquired virus infections. [5, 7-9] Clinical trials were therefore conducted in which a variety of different human and animal viruses were administered to cancer patients.[5, 10-14] Most often, these viruses were arrested by the host immune system and did not significantly impact tumor growth.[15] However, in a few immunosuppressed patients, the infection "took" and tumors regressed, although all too often, this was associated with unacceptable morbidities due to infection of normal tissues. Attempts to address the specificity problem continued throughout the 1950s and 1960s but the results, although encouraging, were not compelling, and with the advent of anticancer chemotherapy, the concept of using replication competent viruses as anticancer agents was largely eclipsed.[5] However, by the 1980s it was clear that even the combination of surgery, radiotherapy, and anticancer chemotherapy was failing to 
substantially impact cancer mortality and with the advent of modern virology accompanied by powerful reverse genetic systems, there came a resurgence of interest in oncolytic viruses.[16-19] During the past two decades, oncolytic virotherapy has reestablished itself as a respectable field of research and there are new numerous ongoing early phase clinical trials testing a wide variety of oncolytic viruses representing many virus families.[3, 20-26]

\section{Why Attenuated Measles Viruses are Attractive Oncolytic Agents}

Safety concerns arising from the use of oncolytic viruses for human cancer therapy can be divided into two areas: risk to the patient and risk to the population.[27] To minimize risk to the patient, an ideal oncolytic virus should be selective for the tumor, nonpathogenic for normal host tissues, non-persistent and genetically stable. To minimize risk to the population, in addition to the above characteristics, the virus should be non-transmissible and preferably derived from a virus to which the population is generally immune.[28]

Attenuated measles viruses fulfill the above requirements. During the past fifty years, live attenuated measles viruses have been administered as vaccines to more than a billion people and the safety record has been outstanding.[29] [26] Very occasionally, in people with severely compromised immune functions, the viral vaccine has propagated and caused disease in the recipient. However, even in this extreme circumstance, as in the case of an HIV-infected patient with virtually no CD4 lymphocytes who succumbed to measles pneumonia nine months after vaccination,[30] there was no evidence that the offending virus had reverted to a pathogenic phenotype capable of spreading and causing disease in normal people.

\section{Tumor Targeting through CD46 Density Discrimination}

Wild-type pathogenic and attenuated measles viruses have different receptor tropisms.[31] Most importantly, attenuated vaccines strains such as MV-Edm are capable of using CD46 as a cell entry receptor.[32,33] Wild-type measles viruses do not, in general, use CD46 as a cell entry receptor, but acquire the CD46 tropism during tissue culture adaption via a mutation in the $\mathrm{H}$-attachment protein coding sequence that changes the amino acid at position 481 in the H-protein, from asparagine to tyrosine.[34-36] Attenuated measles virus strains carrying this mutation are typically selected when wild-type measles stocks are applied to CD46 positive SLAM negative cell monolayers (for example, Vero cells).[37] CD46, also known as membrane cofactor protein, is ubiquitously expressed by all human cells except erythrocytes. [38] CD46 plays an important role in protecting autologous cells from complement attack by serving as a cofactor for Factor I-mediated inactivation of C3b and $\mathrm{C} 4 \mathrm{~b}$, thus blocking the complement cascade at the $\mathrm{C} 3$ activation stage. [39] Fortuitously for those wishing to use attenuated measles as a oncolytic agent, CD46 is frequently overexpressed on human cancer cells compared with their normal non-transformed counterparts, possibly as a mechanism to protect the cancer cells from complement mediated lysis.[40-43] Overexpression of CD46 has been documented in gastrointestinal, hepatocellular, colorectal, endometrial, cervical, ovarian, breast, renal, and lung carcinomas, also in leukemias and multiple myeloma, and has been found to limit the therapeutic potential of monoclonal antibody therapy.[43-54]

CD46 mediates not only the attachment and entry of attenuated measles viruses, but also drives the process of virus induced cell-to-cell fusion between a virus infected cell and its neighboring cells. Using engineered Chinese hamster ovary (CHO) cells expressing a range of CD46 densities, it was shown that intercellular fusion between infected and uninfected cells was minimal at low CD46 receptor density, but increased dramatically above a threshold CD46 expression level.[55] Virus entry, by contrast, increased progressively with increasing CD46 receptor density, showing no dramatic all-or-nothing threshold effects. 
Thus, at low CD46 receptor densities typical of normal cells, attenuated measles virus is able to infect but intercellular fusion is negligible. At higher CD46 receptor densities typical of tumor cells, infection leads to extensive intercellular fusion (the classical cytopathic effect of measles virus) culminating in a dramatically increased level of cell killing.[55] In one recent study, the levels of CD46 expression on myeloma cells was found to be much higher $(49,130$ per cell) than levels on corresponding normal bone marrow cells $(7,340$ per cell) from 38 myeloma patients.[44] Potent cytopathic effects of extensive intercellular fusion were observed in the myeloma cells after measles infection, but not in the normal bone marrow cells (Figure 1). Also, the extent of measles virus induced cell fusion varied from patient to patient, but correlated with CD46 expression levels on the myeloma cells, colony forming assays demonstrated that measles was not cytotoxic to the normal bone marrow progenitor cells.[44] Discrimination between cells with high and low CD46 receptor densities provides a compelling basis for the oncolytic specificity of attenuated measles viruses and establishes them as a highly promising CD46 targeted cancer therapeutic agent. $[44,55]$

There may be additional factors contributing to the tumor specificity of attenuated measles virus besides CD46 receptor density. One possible contributing factor could be a higher intrinsic membrane fusogenicity in tumor cells, making them more likely to undergo intercellular fusion when infected by measles virus, regardless of the surface density of CD46.[44] Another factor might be that there are deficiencies in the innate antiviral responses of tumor cells that render them more highly susceptible to virus infection. [56] For example, the interferon- $\alpha / \beta$ and RNA-dependent protein kinase response pathways are often impaired in tumor cells but not in normal cells, and this is the mechanism underlying the tumor selectivity of a number of RNA viruses currently being tested for cancer therapy, such as vesicular stomatitis virus and reovirus.[18,57-59] These same innate viral control mechanisms may also serve, albeit to a lesser extent, to control the propagation of attenuated measles viruses.

\section{Safety to Population}

The main public safety concern associated with the therapeutic use of an oncolytic virus is accidental emergence of a new viral pathogen capable of epidemic spread in the human population.[27, 28] Serious epidemics arise when pathogenic viruses gain access to susceptible populations under conditions which favor transmission between individual members of the population. In selecting a virus from which to develop an oncolytic antitumor agent for human use, consideration should be given to its mutability, potential pathogenicity, potential transmissibility, and prevalence in the population. As mentioned above, even though the measles vaccine has been given to more than one billion people over the past fifty years, there has never been yet a documented reversion to wild-type measles. [29] Moreover, in contrast to viruses such as influenza which are inheritantly unstable, requiring new vaccines every year, measles virus has remained very stable and has been effectively controlled by essentially the same vaccine for decades.[60] Even if one considers the worst case scenario wherein an attenuated measles virus used for cancer therapy might revert back to wild-type pathogenic strain, the risk of virus transmission from patients to carers and then into the population is limited by the high prevalence of anti-measles immunity. At the current time because of the successful childhood measles vaccination programs which give lifelong protection, more than $80 \%$ of the people in the world are currently measles immune.[61] For this reason, attenuated measles viruses raise significantly fewer safety concerns than oncolytic viruses derived from other virus families. 


\section{Oncolytic Activity of Wild-Type and Attenuated (Vaccine Strain) Measles Viruses}

Occasional "spontaneous" tumor regressions of Hodgkin's disease and Burkitt's lymphoma have been documented after measles infections.[7, 8, 62-64] Perhaps the most compelling was the case history of an 8-year old African boy who presented to a clinic in Uganda with a four month history of painless right orbital swelling. A biopsy specimen of the right retroorbital tumor was histologically diagnostic of Burkitt's lymphoma but at the time of planned initiation of therapy, he was noted to have a generalized measles rash. On the same day, the right orbital tumor was noted to be regressing and because of the presumed measles infection, he was given no chemotherapy for the Burkitt's lymphoma. During the course of the next two weeks, his rash disappeared and he seroconverted to measles. At the same time, the tumor regressed completely and remained in complete remission for at least four months after the measles infection in the absence of antineoplastic therapy. The mechanism underlying the rapid tumor regression that was observed in this remarkable case history was never elucidated but Burkitt's lymphomas are known to express high levels of SLAM and are therefore susceptible to infection by wild-type measles viruses.[65, 66] The timing of the regression, coinciding with the period during which measles virus burden and measlesinduced immunosuppression are at their peak, supports the contention that the tumor cells were directly destroyed by the virus.

It could be argued on the basis of case histories such as the one described above that there would be some value to treating cancer patients with a wild-type pathogenic strain of measles. However, there are strong safety and efficacy arguments against this. From a safety perspective, measles is a serious and unpleasant illness which is highly transmissible to nonimmune subjects and is sometimes fatal.[60] Regarding efficacy, as discussed previously, most human malignancies lack receptors for wild-type measles viruses[67] and therefore, are not even theoretically susceptible to its possible oncolytic actions. Attenuated vaccine strains of measles virus, by contrast, have far greater appeal as possible oncolytic agents for intentional administration to human cancer patients. Most of the measles vaccine strains in current use belong to the Edmonston lineage which comprises a number of closely interrelated laboratory-adapted substrains derived from a 1954 clinical isolate (from the throat of a child named David Edmonston) that has been passaged extensively in tissue culture, resulting in a loss of pathogenicity.[36, 60, 68] The MV-Edm vaccine was initially licensed in 1963 but was found to be reactogenic, causing fever and rash in measles-naïve children. $[69,70]$ The virus was passaged further in other cells, including chick embryo fibroblasts, giving rise to more highly attenuated vaccine strains, including MV-Moraten which was licensed as Attenuvax in the United States in 1968 and the Edmonston-Zagreb strain (MV-EZ), a strain which has been used extensively in Europe.[29] In contrast to wildtype measles viruses, all the laboratory-adapted Edmonston strains of measles virus have acquired the ability to use CD46 as a receptor to mediate virus entry and intercellular fusion. $[32,33,37]$

Preclinical studies to test the oncolytic potential of attenuated Edmonston lineage viruses were first conducted at the turn of the $20^{\text {th }}$ century using a genetically modified derivative of the Edmonston-B strain (MV-Edm tag) that was rescued from a molecular clone of the viral genome and was subsequently amplified on Vero cells.[71] The Edm-tag strain and its genetically engineered derivatives (see below) were found to be selectively destructive to human tumor cells in culture[44] and showed promising antitumor activity in several mouse xenografts models of different human malignancies including lymphoma, multiple myeloma, ovarian, colorectal, breast, liver cancer and glioma.[72-78] However, clinical testing of these engineered measles strains presented considerable logistic challenges, including the need to develop new manufacturing processes, validate the clinical products, and perform extensive toxicology testing to confirm their safety. For these reasons, there was a strong impetus to take the simple path and explore the possibility of using agents that 
had already been approved for human use, such as the Moraten and Edmonston-Zagreb measles vaccines, as oncolytic agents for cancer therapy. For this reason, the oncolytic potential of the commercially available Moraten measles vaccine was tested in a murine intraperitoneal model of human ovarian cancer and was compared with the efficacy of a recombinant MV-Edm tag derived viral strain.[79] In vitro, the Moraten strain was able to infect human ovarian cancer cells, but caused intercellular fusion with greatly delayed kinetics compared to the MV-Edm tag strain. However, in vivo studies in ovarian cancer models showed that both viruses had equivalent antitumor potency causing significant prolongations in survival after intraperitoneal administration of a total dose of $10^{6}$ infectious units.[79] Unfortunately, since the Moraten vaccine is packaged and sold commercially in doses of only $10^{3} \mathrm{TCID}_{50}$ it was considered impractical to proceed to a clinical trial in which, it was anticipated, MV-Moraten doses in excess of $10^{8}$ TCID $_{50}$ (i.e., 100,000 times the vaccination dose) would be required for oncolytic efficacy.

While there have been no human studies evaluating the oncolytic potential of the MVMoraten vaccine strain, a Phase I clinical study using the Edmonston-Zagreb vaccine strain was conducted in Zurich in patients with cutaneus T-cell lymphoma.[80] A total of five patients were enrolled in this study and the Edmonston-Zagreb vaccine strain of measles virus was administered directly into accessible cutaneous tumors for up to a total of four doses. Each virus injection was preceded by two subcutaneous injections of interferon-alpha ( 9 million units subcutaneously), at 72 hours and 24 hours previously. This was a dose escalation study with a minimum intratumoral dose of 100 TCID $_{50}$ and a maximum dose of $1,000 \mathrm{TCID}_{50}$ of the MV-Edmonston-Zagreb virus. The treatment was very well tolerated and five of six MV-injected lesions showed clear regression. In two of the patients distant non-injected lesions improved, but they remained unchanged in the other three of five. In all five patients there was a slight increase in the anti-measles antibody titer after therapy. These very promising data were published in October 2005 and follow-on studies are eagerly awaited.[80]

\section{Engineering Attenuated Measles Viruses to Enhance Their Utility as Oncolytic Agents}

A reverse genetic system for the generation of recombinant measles viruses derived from MV-Edm tag was first reported in 1996.[71] This opened the door for the generation of recombinant measles viruses encoding additional transcription units as well as the engineering of viral structural and nonstructural protein coding sequences to modulate virus biology (Figure 2). Genome engineering has therefore emerged as an important approach whereby new versions of the MV-Edm tag virus can be generated as a way to enhance its performance in cancer therapy. Efforts to date have focused on the generation of recombinant viruses whose in vivo spread can be noninvasively monitored as well as the generation of viruses that can more effectively combat host innate immune responses or that can more accurately recognize and destroy neoplastic tissues. Each of these approaches is discussed separately below.

\section{Noninvasive monitoring of measles virus spread}

Pharmacokinetics describes the fate of a drug in the body including its absorption, distribution, biotransformation, and excretion. Unfortunately, pharmacokinetic issues have not been adequately addressed in previous human virotherapy studies and this is proving to be a significant impediment to the intelligent clinical development of these agents. Ideally, it should be possible to noninvasively monitor the in vivo spread and elimination of an oncolytic virus in a treated cancer patient, and to determine the profile of viral gene expression over time. In the absence of data on virus kinetics, it is not possible to know 
whether a failed response to therapy is due to lack of infection, inadequate virus spread, weakened cytopathic effect, or premature virus elimination. Noninvasive monitoring should therefore be an integral component of human studies of oncolytic measles viruses and has the potential to facilitate the tailoring of virotherapy protocols for individual patients.

Two approaches have been taken to facilitate in vivo monitoring of the spread of oncolytic measles viruses (Figure 2). In the first approach, additional transcription units coding for soluble marker peptides were inserted into the viral genome.[81] It was reasoned that ideal marker peptides should be non immunogenic with no biological function and a constant circulation half life. They should also be efficiently secreted from virus infected cells into the blood stream. The soluble extracellular domain of human carcinoembryonic antigen (CEA) and the $\beta$-subunit of human chorionic gonadotrophin ( $\beta \mathrm{hCG}$ ) were therefore chosen for this approach. Oncolytic measles viruses expressing each of these transgenes from an additional transcription unit inserted upstream of the $\mathrm{N}$ gene were constructed.[81] The marker peptides did not compromise virus replication and the kinetics of virus propagation in CD46 transgenic mice could be easily followed by measuring concentrations of the virally encoded marker peptides in serum. When mice bearing human tumor xenografts were challenged with the trackable viruses, different kinetic profiles of marker gene expression could be correlated with distinct therapeutic outcomes.[81, 82] In subsequent studies, the MV-CEA virus was shown to retain its potent oncolytic activity in preclinical models of ovarian cancer[74, 83] and subsequently in brain cancer[75] which provided the impetus for its advancement to Phase I clinical testing in patients with each of these malignancies (see below).

While virally encoded soluble marker peptides do provide for noninvasive monitoring of the total burden of virus infected cells and tissues in the body, they do not provide any anatomical information about the location of virus infected cells (Figure 2). To this end, a second recombinant measles virus was generated coding for the human thyroidal sodium iodide symporter (NIS).[84] NIS is a membrane ion channel expressed on thyroid follicular cells which efficiently transports iodine (required for thyroxin production) into cells against its concentration gradient.[85] Thyroidal NIS expression has been exploited for more than fifty years in clinical practice for thyroid imaging (with I-123) or ablation (with I-131) and for systemic therapy of well differentiated thyroid malignancies.[86, 87] MV-NIS infected cells are able to concentrate radioactive iodine from the bloodstream, enabling the status of an infection to be monitored by serial noninvasive single photon emission computed tomography (SPECT) or positron emission tomography (PET) imaging using I-123 or I-124 as tracers respectively.[88, 89] The approach has been used for noninvasive monitoring of intratumoral virus propagation in preclinical models of multiple myeloma, pancreatic, hepatocellular, and ovarian carcinoma, and has further been used to enhance the therapeutic potency of measles virotherapy by judiciously timed administration of the $\beta$-emitting radioiodine isotope I-131.[76, 83, 84, 89, 90] Interestingly the recombinant measles virus in which NIS was inserted between the $\mathrm{H}$ and L cistrons is able to propagate as efficiently as the MV-Edm tag strain from which it was derived and is potently oncolytic even in the absence of I-131.[84] Based on these favorable characteristics, the MV-NIS virus has been advanced to Phase I clinical testing in patients with multiple myeloma (see below)

The interaction of a replicating measles virus with tumor cells and with the host immune system represents a complex dynamical system that can be analyzed mathematically as a problem in population dynamics. $[91,92]$ The outcome of this type of therapy depends in a complex way on the intricate interactions between the various populations involved and modeling of the kinetics of virotherapy may aid in improved understanding of treatment outcomes and in the design of improved therapeutic protocols. Mathematical models of cancer virotherapy with recombinant measles viruses and of radiovirotherapy using the 
combination of MV-NIS and radioactive I-131 have been developed and provide a reasonably good fit to experimental data.[91, 93]

\section{Arming the Virus to Combat Innate Immunity}

Pathogenic measles viruses are capable of combating the cellular innate immune response. They do this by means of the P/VC proteins encoded in the phospho protein $(\mathrm{P})$ transcription unit.[94] The $\mathrm{P}$ and $\mathrm{V}$ proteins are particularly implicated in measles immune evasion and have been shown to inhibit interferon-induced STAT nuclear translocation and to suppress STAT1 and STAT2 phosphorylation.[95-98] Attenuated measles viruses are typically mutated in their $\mathrm{P}$ and $\mathrm{V}$ proteins and are therefore unable to efficiently suppress innate immune responses. [99] As a consequence, wild-type measles isolates induce significantly lower release of interferon upon infecting peripheral blood lymphocytes when compared to attenuated strains.[99, 100]

As a general rule, tumor cells are thought to have defects in their interferon response pathways such that they are unable to mount effective innate antiviral responses.[101] However, this is not an absolute deficiency. Oncolytic measles viruses derived from the MV-Edm tag infectious clone were shown to induce significantly higher levels of interferon in both normal and tumor cells when compared to a wild-type measles virus.[102] Moreover, pretreatment of tumor cells with interferon prior to measles infection did significantly compromise viral gene expression. Based on these observations, a chimeric measles virus based on the Edm-tag platform, but armed with a wild-type P-gene, was generated and evaluated both in vitro and in vivo for antineoplastic activity.[102] As expected, the chimeric virus exhibited a reduced capacity to induce interferon in infected cells, and when intravenously administered to SCID mice bearing human myeloma xenografts, showed greater oncolytic potency. This study served to emphasize that oncolytic measles viruses can be subject to control by the innate immune defenses of human tumor cells and may therefore be more effective when engineered to rearm them with wild-type proteins that silence the innate immune response. This engineering strategy does raise the legitimate concern that rearming an attenuated measles virus with a wild-type P-gene to permit more effective immune evasion may generate a more pathogenic agent and thereby compromise patient safety. However, measles virus virulence and pathogenicity are known to be complex and does not depend solely on P/V/C proteins.[103] Clinical testing of oncolytic measles viruses that have been engineered to more effectively combat the innate intracellular immune response is not currently being pursued. However, depending upon the clinical outcomes (i.e., efficacy versus toxicity) of ongoing clinical trials which are using highly attenuated measles viruses, there may be a good rationale for testing such fortified viruses in the future.

\section{Engineering Measles Virus Tropism}

At this time, measles is still the only virus that can be efficiently retargeted through a broad range of cellular receptors without significant reductions in entry efficiency.[26, 104] However, while the retargeting of measles virus entry is without question an extraordinary technical triumph, its utility has yet to be proven. The original rationale for attempting to redirect the tropisms of oncolytic measles viruses was the incorrect assumption that, because it is expressed ubiquitously, CD46 would not be tumor selective. However, as outlined previously, the oncolytic strains of measles virus in current use do efficiently discriminate between the high density of CD46 expressed on tumor cells and the lower densities of this receptor present on non-transformed cells. [44, 55, 74] As such, these viruses already discriminate and selectively destroy cancer cells by targeting CD46. For this reason, unless significant toxicities arising from collateral damage to normal tissues are encountered in ongoing clinical studies using the non-targeted viruses MV-CEA and MV-NIS in patients 
with ovarian cancer, glioma, and multiple myeloma, it will be difficult to justify the use of fully retargeted viruses. However, it is possible that certain tumor types will prove to have lower levels of CD46 receptor expression, in which case there may be a stronger case for using viruses with alternative, engineered receptor tropisms. In addition, for intravenously administered viruses, the ability to interact with the lumenal surface of vascular endothelial cells lining tumor blood vessels might lead to significant enhancements in virus uptake at sites of tumor growth.

Initial efforts to engineer foreign polypeptides into the measles virus coat were focused on the Fusion (F) protein. But even small modifications to the extreme N-terminus of this protein completely destroyed its ability to provide fusion support (Morling F and Russell SJ, unpublished). In contrast to the F protein, the Hemagglutinin (H), a type II membrane glycoprotein, was able to tolerate the insertion of large polypeptides sequences at or close to its extreme $\mathrm{C}$-terminus without compromising its ability to be incorporated into virus particles and to provide fusion support functions. Building upon this observation, recombinant viral genomes coding for chimeric $\mathrm{H}$-glycoproteins with a variety of different C-terminal extensions were constructed and rescued as recombinant infectious viral particles. In this way, it was possible to display a wide variety of different ligands on the viral surface, including growth factors (human EGF and IGF 1), single-chain antibodies (against CEA CD38, CD20, EGF receptor, and others), single-chain T cell receptors, and snake venom peptides such as Echistatin. [105-110] In each case the recombinant viruses were shown to display multiple copies of the respective polypeptides on the surface and were endowed not only with new binding specificities, but also with expanded tropisms. Thus each recombinant virus was able to bind and enter cells via its targeted receptor and thereafter to drive the process of intercellular fusion between the infected cell and neighboring receptor positive cells.

Having determined that the tropisms of recombinant measles viruses could be expanded by surface display of cell binding polypeptides, the next step was to engineer the underlying $\mathrm{H}$ protein to ablate the natural virus tropisms for CD46 and SLAM. [111, 112] Several different mutations known to interfere with binding to either CD46[35, 113] or SLAM[111] were therefore engineered into an $\mathrm{H}$-expression construct coding for a chimeric $\mathrm{H}$-protein displaying a single-chain antibody against CD38. Numerous different permutations of CD46 and SLAM ablating mutations were tested in a screening system, wherein the $\mathrm{H}$-expression constructs were co-transfected with an F-expression plasmid into cells expressing receptors for CD46, SLAM, or CD38 respectively.(Nakamura T and Russell SJ, unpublished) In this way, a construct with mutations at residues 481 (Y to A) and 533 (R to A) was found to efficiently mediate antibody targeted cell fusion, even when the displayed domain was replaced with single-chain antibodies recognizing alternative cellular targets (EGFR and EGFRvIII).[112] Subsequently, these fully retargeted $\mathrm{H}$-coding sequences were engineered into recombinant measles virus genomes and the corresponding viruses were recovered. [114] In each case, recombinant viruses displaying single-chain antibodies on a doubly ablated H-protein displayed the expected (fully retargeted) host range properties and could be used to mediate targeted destruction of tumors expressing the appropriate cognate receptor in living mice.

One technical issue associated with the rescue and propagation of fully retargeted viruses was the requirement that the targeted receptor should be expressed on the cells being used as a substrate for virus growth. This was addressed in two ways, either by generating Vero cells expressing the targeted receptors[114] or, alternatively, by means of a pseudo receptor system using Vero-a His cells expressing a membrane anchored single-chain antibody that recognizes a hexahistidine peptide (H6).[115] The H6 peptide was then incorporated at the extreme C-terminus of the chimeric $\mathrm{H}$-proteins of fully retargeted viruses, such that they 
could be efficiently rescued and propagated on the Vero-a His cells.[66] This system has subsequently been used to generate fully retargeted viruses displaying single-chain antibodies with diverse receptor specificities. At the current time, the list includes viruses retargeted to CD38, EGFR, EGFRvIII, a-folate receptor, HER2/neu, CD20, CD19, CD52, prostate specific membrane antigen (PSMA) and the myeloma antigens HM1.24 and Wue-1. (Russell SJ, unpublished) [66, 116-120] Interestingly, where tested, the new tropisms conferred on measles viruses by displayed scFvs are stably maintained during multiple serial virus passages without reversion to native receptor usage. While one conclusion from the aforementioned studies is that measles virus has a remarkably flexible and adaptable entry mechanism that can utilize multiple alternative cellular receptors, it has also become apparent that there can be significant differences in the efficiency of virus entry and intercellular fusion depending on the precise specificity and affinity of the displayed ligand. To further explore the relationship between the affinity of a displayed ligand for its targeted receptor and the behavior of the retargeted viruses, a panel of six recombinant HER2/neu retargeted measles viruses was generated displaying a panel of single-chain antibodies with identical HER2/neu receptor specificities but with dissociation constants ranging from $1.6 \times$ $10^{-6} \mathrm{M}$ to $1.5 \times 10^{-11} \mathrm{M}$.[117] Comparisons of the infectivities and cytopathic effects of these viruses on a panel of cell lines expressing different surface densities of the HER2/neu receptor gave quite unexpected results, showing that there was a functional threshold affinity level above which infection and intercellular fusion proceeded with equal efficiency, even when affinity increased over 1,000-fold above the threshold level. Below the threshold, infection was minimal. This affinity threshold was shown to correlate inversely with receptor density such that higher affinities were required to fuse cells with lower receptor densities. Thus, depending on their receptor affinities, retargeted measles viruses are able to discriminate efficiently between cells expressing different densities of a targeted receptor. [117]

Several in vivo therapy studies have been published in which fully retargeted viruses have been administered to mice bearing human tumor xenografts by intratumoral, intraperitoneal, or intravenous routes resulting in retardation of tumor growth and prolongation of survival. Examples include the use of measles viruses targeted to EGF receptor in ovarian cancer and glioma models, viruses targeted to the a-folate receptor in an ovarian cancer model, EGFRvIII targeted viruses for glioma, and CD38 or CD20 targeted viruses for the treatment of two different mouse lymphoma models.[66, 116, 119-121] In general, the retargeted viruses showed at least equivalent antitumor activity compared to the parental MV-Edm tag strain, but with reduced capacity to cause damage to the brains of CD46 transgenic mice.

As discussed previously, it is still an open question whether fully retargeted measles viruses can offer therapeutic advantages over the CD46 specific viruses that are currently undergoing clinical testing. However, it is hoped that measles viruses that can interact more efficiently with markers expressed on the lumenal surfaces of the endothelial cells lining tumor blood vessels will more efficiently localize to sites of tumor growth when infused into the bloodstream. Exploratory studies using measles viruses displaying av $\beta_{3}$ integrin binding peptides (cyclic RGD and Echistatin) as extensions of their H proteins have shown that they can, at least, interact with the lumenal surface of developing neovessels in the chick chorioallantoic membrane and that they can be transcystosed across the vascular endothelium of these vessels into the interstitial space (Peng KW and Russell SJ, unpublished).

\section{Clinical Translation of Recombinant Oncolytic Measles Viruses}

Of the recombinant measles viruses discussed in the previous section, two (MV-CEA and MV-NIS) are currently being administered to cancer patients in Phase I clinical trials. MV- 
CEA is being infused into the peritoneal cavities of patients with advanced treatment refractory ovarian cancer, and in a second trial, is being administered into the tumor bed after surgical excision of high-grade tumors of the brain. MV-NIS is being administered intravenously to patients with advanced treatment refractory multiple myeloma. Approval for these clinical protocols was, in each case, preceded by a detailed FDA review of the clinical protocol design, the manufacturing process, the purity, identity, and sterility of the manufactured product, the results of preclinical efficacy studies, and the results of comprehensive toxicology and biodistribution studies conducted in appropriate animal models.

\section{Manufacture}

Based on the doses of MV-CEA and MV-NIS that were required to mediate tumor regression in mouse xenograft models of human cancer, it was projected that doses of virus in the region of $10^{9} \mathrm{TCID}_{50}$ would be required for clinical efficacy. A single dose of the Moraten measles vaccine contains somewhere between $10^{3}$ and $10^{4} \mathrm{TCID}_{50}$ and existing manufacturing processes used by major measles vaccine suppliers were unsuitable for the generation of high titer viral stocks required for oncolytic applications.[79] A new process was therefore developed for the scaled manufacture and partial purification of oncolytic measles viruses using the immortal Vero cell line as substrate. Manufacture of clinical grade lots of both MV-CEA and MV-NIS was then completed in a pilot manufacturing facility at Mayo Clinic Rochester, adhering to the principles of Good Manufacturing Practices (GMP).

\section{Choice of Animal Models for Toxicology Studies}

Because they are derived from attenuated laboratory adapted strains of measles virus, the host range properties of MV-CEA and MV-NIS are quite distinct from those of wild-type pathogenic measles virus strains. As mentioned previously, these viruses efficiently exploit CD46 as a receptor for binding, cell entry and cell fusion and this receptor usage is a critical factor influencing the choice of an appropriate animal model for pharmacology and toxicology studies. As for other vaccine strains of measles viruses, because they are highly attenuated (i.e., non pathogenic) there is no model in which to study their pathogenesis. The three animal models that have proven to be of some considerable value for FDA mandated preclinical studies of biodistribution and toxicity are Rhesus monkeys (Old World primates), squirrel monkeys (New World primates), and interferon $\alpha / \beta$ receptor knockout CD46 transgenic mice.

CD46 transgenic mouse models were originally created in the hope that they might facilitate the study of measles virus pathogenesis. [122-124] However dissemination of viruses belonging to the Edmonston lineage has only ever been observed in CD46 mice lacking the interferon $\alpha / \beta$ receptor (IFNAR ${ }^{\mathrm{ko}} \mathrm{xCD} 46-\mathrm{Ge}$ ). $[125]$ These mice express human CD46 in a tissue distribution that mimics the pattern of CD46 expression in humans, including low to absent of expression on erythrocytes.[122, 126] After intranasal challenge with MV-tag the animals showed local virus replication in the respiratory epithelium followed by dissemination via the lymph node system, similar to the pattern of wild-type measles virus dissemination in the human host.[122,125] Infection of cells of the monocyte macrophage lineage is prominent in this model.[125, 127]

An alternative and better established model for the study of measles virus pathogenesis is the Rhesus monkey which, like other Old World non-human primates, develops a measleslike illness when challenged with wild-type measles virus.[128, 129] However, Rhesus monkeys do not provide, by any means, a perfect model in which to test the virulence of tissue culture adapted measles viruses that use CD46 as a receptor.[128, 130-132] Previous studies have shown repeatedly that Rhesus monkey virulence studies of attenuated measles 
viruses are not predictive of their reactogenicity (i.e., the ability to cause measles-like illness) in humans.[133-136] Numerous attenuated measles viruses have been tested in primates during the development of new measles virus vaccines [136-138] and despite the fact that they have scored completely negative in this Macaque-virulence test, they have proven to be reactogenic in humans, causing a morbilliform rash, often accompanied by fever and malaise in a high percentage of recipients.[133-136] The key deficiency of the Macaque-virulence model is that the tissue distribution of CD46 in Macaque differs significantly from humans. Most importantly, CD46 is abundant on Macaque red blood cells, but is absent from human red blood cells.[139] CD46 binding strains of measles virus, therefore, are agglutinated on Macaque, but not human red blood cells, an interaction that most likely impedes virus dissemination in the primates. The Macaque model was therefore considered to be suboptimal for toxicity studies in which recombinant measles viruses are administered into the bloodstream, but was considered relevant when studying the toxicity of intracerebral MV-CEA (see below).

Unlike Old World primates, New World primates, such as the squirrel monkey (Saimiri sciureus) express a truncated CD46 molecule to which MV-Edm does not attach.[139] The red cells of New World monkeys are, therefore, not agglutinated by attenuated measles viruses but these animals do get a measles-like illness when challenged with wild-type measles virus, making them an informative model in which to test the toxicities of oncolytic measles viruses arising from their interactions with the wild-type measles receptor SLAM. Squirrel monkeys challenged with wild-type measles virus develop a classical measles-like illness characterized by fever, coryza rash, immunosuppression, and subsequent recovery. [128]

\section{Pharmacology / Toxicology Testing of MV-CEA and MV-NIS}

To support the first clinical protocol, a Phase I trial of intraperitoneal administration of MVCEA in patients with recurrent ovarian cancer, the formal biodistribution and toxicology studies were conducted in IFNAR ${ }^{\mathrm{ko}} \mathrm{xCD} 46-\mathrm{Ge}$ mice.[127] The key findings were that MVCEA administered into the peritoneal cavity efficiently infected peritoneal macrophages and these trafficked to abdominal draining lymph nodes, as well as to the marginal zones of the spleen. CEA expression peaked between days 2 and 5 and returned to baseline by day 10 , due to virus elimination. There was no evidence of virus shedding in the urine or respiratory secretions, but there was some evidence for long-term persistence of viral genomes in the spleens of infected animals. Measles viruses encoding different marker genes were also employed for biodistribution studies and green fluorescent protein proved to be highly informative. Mesothelium and ovarian surface epithelium were remarkably resistant to infection but peritoneal macrophages were susceptible. Large numbers of infected macrophages could be detected in the greater omentum concentrated in "milky spots". Infected macrophages were also identified outside the peritoneal cavity at diaphragmatic stomata along lymphatic vessels and in the parathymic lymph nodes. Eventually, the cells escaped into the blood stream and could be identified in the marginal zones of the white pulp of the spleen.

In toxicology studies, MV-CEA was administered into the peritoneal cavity (maximum dose $10^{7} \mathrm{TCID}_{50}$ ) and the animals were closely monitored for activity level, general appearance, body weight, key hematological and biochemical parameters, and serum CEA levels (Peng KW, Myers RM and Russell SJ, unpublished). Necropsies were conducted on days 14, 28 , and 91 after virus administration and all organs were sent for histopathological analysis. The study was essentially negative with no significant toxicities encountered at any dose level. Dose response studies in a SKOV3.ip1 intraperitoneal ovarian cancer xenograft model revealed that the virus was equally effective over a wide range of dose levels, from $6 \times 10^{7}$ 
down to $6 \times 10^{3} \mathrm{TCID}_{50}$. Analysis of CEA profiles in the treated mice was highly informative, illustrating the variability of virus kinetics at different dose levels. The highest doses of virus were associated with higher initial levels of tumor cell killing, but the final outcome of MV-CEA therapy at all dose levels was a partial equilibrium between virus and tumor, resulting in significant slowing of tumor growth and enhanced survival of the mice[140].

In support of the Phase I brain cancer study of intratumoral and/or resection cavity administration of MV-CEA in patients with recurrent glioblastoma multiforme, toxicology studies were conducted both in IFNAR ${ }^{\mathrm{ko}} \mathrm{xCD}$ 46-Ge mice and in Rhesus monkeys.[141] In both cases, the virus was delivered by intracerebral inoculation and animals were carefully observed for signs of neurological impairment or other organ damage. MV-Edm is known to be neuropathogenic in measles-naïve IFNAR ${ }^{\mathrm{ko}} \mathrm{xCD} 46-\mathrm{Ge}$ mice and the animals were therefore pre-immunized by intraperitoneal administration of MV-GFP for one month prior to the initiation of toxicology. The animals were closely monitored for 90 days after intracerebral inoculation with MV-CEA but there was no evidence for neurotoxicity, neither clinically nor upon histological examination of brain sections at various timepoints after virus administration. For toxicity testing in monkeys, five adult measles-immune Rhesus Macaques received intracerebral injections of MV-CEA $\left(10^{5}\right.$ or $\left.10^{6} \mathrm{TCID}_{50}\right)$ or vehicle control into the frontal lobe on days 1 and 5. The animals were monitored closely thereafter. Monitoring studies included clinical observation, analysis of blood samples, throat swabs, and cerebral-spinal fluid and MRI imaging of the brain. There was no evidence in this study for MV-CEA-mediated neurotoxicity.

In support of the Phase I clinical trial testing intravenous administration of MV-NIS, with or without cyclophosphamide, in patients with multiple myeloma, preclinical pharmacology and toxicology studies were conducted in SCID mice bearing subcutaneous myeloma xenografts, non-tumor bearing IFNAR ${ }^{\mathrm{ko}} \mathrm{xCD} 46-\mathrm{Ge}$ mice, and in measles-naïve squirrel monkeys.[142] Dose response studies conducted in the KAS-6/1 myeloma xenograft model demonstrated that a single intravenous dose of $4 \times 10^{6} \mathrm{TCID}_{50}$ per kilogram of MV-NIS was the minimum dose that reliably led to tumor regression and prolongation of survival. Toxicity studies in IFNAR ${ }^{\mathrm{ko}} \mathrm{xCD} 46-\mathrm{Ge}$ mice were negative up to a single intravenous dose of $4 \times 10^{8} \mathrm{TCID}_{50}$ per kilogram. A single dose of cyclophosphamide given prior to virus administration did significantly impede the antiviral immune response in this model, leading to delayed virus elimination. Virus associated toxicities were not observed in measles-naïve squirrel monkeys, even at very high intravenous doses of $10^{8} \mathrm{TCID}_{50}$ per kilogram of MVNIS given alone or in combination with cyclophosphamide. Viral mRNA was detected in cheek swabs harvested from the squirrel monkeys on days 1, 2, 8, 15, and 22 after MV-NIS administration and copy numbers were higher at all timepoints in the cyclophosphamide treated animals with peak levels seen on day 8 . Based on these studies, a safe starting dose of MV-NIS for the clinical protocol was set at 1.5 by $10^{4} \mathrm{TCID}_{50}$ per kilogram $\left(10^{6} \mathrm{TCID}_{50}\right.$ per patient $)$ increasing to a maximum of $1.5 \times 10^{7} \mathrm{TCID}_{50}$ per kilogram $\left(10^{9} \mathrm{TCID}_{50}\right.$ per patient) with a single-dose of 10 milligrams per kilogram cyclophosphamide administered 24 hours earlier by intravenous infusion.

\section{Current Status of Clinical Trials}

Each of the three Phase I clinical trials discussed above is progressing satisfactorily. The first patient to receive a recombinant measles virus had advanced ovarian cancer and received a series of six intraperitoneal infusions of MV-CEA starting in July 2004. To date, 20 patients have been treated in the ovarian cancer study at seven dose levels $\left(10^{3}\right.$ to $10^{9}$ $\mathrm{TCID}_{50}$ ). The study is progressing satisfactorily and the results will be published in the near future. Two patients with glioblastoma multiforme have so far been enrolled into the intracerebral MV-CEA study and six patients with multiple myeloma have been enrolled for 
intravenous administration of MV-NIS at two dose levels $\left(10^{6} \mathrm{TCID}_{50}\right.$ and $\left.10^{7} \mathrm{TCID}_{50}\right)$. Each of these clinical studies is progressing satisfactorily but detailed reports of the trial outcomes will not be published until the trials have been completed.

\section{Enhancing the Efficacy of Oncolytic Measles Viruses: Immune Evasion and Immune Suppression}

For successful virotherapy of disseminated malignancies, oncolytic measles viruses will have to be delivered via the bloodstream. Optimal treatment outcomes will require efficient delivery via the bloodstream to sites of tumor growth and this should be followed by efficient intratumoral spread, leading to tumor destruction. Each of these processes can be severely constrained by anti-measles immunity; delivery by humoral immunity, and spread by cell mediated immunity (Figure 3). Considerable attention has therefore been focused on the use of cells as delivery vehicles to circumvent the humoral anti-measles immune response, and on the use of immunosuppressive drugs to combat cell mediated anti-measles immunity. These two approaches are discussed below.

\section{Use of Cell Carriers to Deliver Oncolytic Measles Viruses to Sites of Tumor Growth}

Irrespective of the presence of antiviral antibodies, many intravenously administered viruses are sequestered in the microcirculations of lung, liver, and spleen, where they are phagocytosed by macrophages.[143, 144] It is the small percentage of intravenously administered viruses escaping this fate that infect the tumor tissue and mediate the regressions that are seen in preclinical models. However, these viruses are highly vulnerable to the neutralizing activities of antiviral antibodies, which have a dramatic titer dependent effect on the speed of virus inactivation.[145, 146] Also, antibody titers increase progressively with each successive exposure to the virus. $[147,148]$ Because of prior measles infection or measles vaccination, approximately $90 \%$ of Americans have protective titers of anti-measles antibodies which may limit the therapeutic efficacy of systemically administered measles viruses.[61, 149] In contrast to the general population, patients with multiple myeloma have profound suppression of their humoral immune-responses and low antibody titers to measles virus, making them ideal candidates for systemic oncolytic measles virus therapy.[150, 151] However, most patients suffering from other cancers do have healthy protective titers of anti-measles antibodies. The protective properties of antimeasles antibodies were well demonstrated in the pre-vaccination era when serum from convalescing measles patients was used as post-exposure prophylaxis for children at risk. $[152,153]$ Interestingly, serotherapy was only effective if administered within six days of measles virus exposure, indicating that it cannot prevent the cell associated viremia and dissemination of measles virus via the bloodstream that occurs towards the end of the incubation period (days 10-14 after initial exposure, coincident with the prodromal symptoms and rash).[29] Importantly, cell free viremia has not been recorded in natural measles infections. $[29,154]$ The virus enters via the respiratory tract, migrates locally to lymphoid tissues and then enters the bloodstream, only inside cells, typically monocytes or lymphocytes which transport it to distant sites where it causes the typical rash and other disease features.[29]

On the basis of the above insights into how measles virus can travel via the bloodstream, even the presence of antiviral antibodies, there is considerable interest in the use of infected cell carriers to deliver oncolytic measles viruses to sites of tumor growth.[155] Not only does this approach have the potential to avoid neutralization by antiviral antibodies, but might also prevent mislocalization of the virus in liver and spleen, as well as aiding extravasation from tumor blood vessels. In vitro studies demonstrated that in contrast to infection by naked virions, heterofusion between infected cell carriers and tumor cells was 
more resistant to antibody neutralization. [156, 157] Moreover, systemic and intraperitoneal injection of measles infected cells successfully transferred infection in vivo to sites of tumor growth (using xenograft models of lymphoma, hepatocellular carcinoma, and multiple myeloma) even in the presence of neutralizing antibodies.[156, 157] Monocytes, endothelial progenitor cells, and $\mathrm{T}$ lymphocytes were also shown to have potential as measles virus carriers, but considerable optimization of the approach is required since, to date, the enhancements in efficacy that have been achieved using this approach have been very small.

\section{Combination Therapy with Oncolytic Measles Viruses and Immunosuppressive Drugs}

There are many drugs with immunosuppressive properties currently being used in the clinic, either for the treatment of autoimmune disease or to suppress the rejection of transplanted organs. Their profiles of activity vary, some being more effective against a particular subset of lymphocytes with others having a broader spectrum of activity. While there is a strong rationale for combining immunosuppressive therapy with oncolytic measles virotherapy, progress in this research endeavor has been hampered by the lack of suitable animal models in which a measles susceptible tumor is allowed to grow in a measles susceptible animal with an intact immune system. However, despite the lack of suitable experimental models, attempts have nevertheless been made to determine whether cyclophosphamide might be capable of suppressing anti-measles immune responses and thereby enhancing its therapeutic potency.

Cyclophosphamide is known to be highly toxic to proliferating lymphocytes and can modulate both primary and anamnestic immune responses to a variety of antigenic challenges, including virus infection.[158] Precise effects vary with the dose of antigen, the dose of cyclophosphamide, and the timing of cyclophosphamide administration relative to the antigenic challenge.[159] Suppression of B-cell and T-cell responses is most pronounced when cyclophosphamide is administered at the same time or within three days following antigen challenge, but is also seen when the drug is administered one or two days before exposure to antigen, particularly when higher doses of cyclophosphamide are used.[160] When a single dose of cyclophosphamide was administered to IFNAR ${ }^{\mathrm{ko}} \mathrm{xCD} 46-\mathrm{Ge}$ mice a few hours prior to intraperitoneal or intravenous injection of MV-CEA or MV-NIS, respectively, elimination of the viruses was substantially delayed and the primary antimeasles antibody response was suppressed. A similar delay in virus elimination was observed when squirrel monkeys were pretreated with cyclophosphamide prior to infusion of MV-NIS and these data provided part of the justification for the ongoing MV-NIS clinical trial in which, in later cohorts, the patients will be pretreated with cyclophosphamide before they receive the virus.[142] Additional preclinical studies were conducted in which cyclophosphamide was compared with other immunosuppressive agents and found to be substantially superior to dexamethasone, an equipotent but less toxic than whole-body irradiation (Myers RM, Peng KW, Russell SJ, unpublished).

Toward the development of an informative immunoincompetent murine model to experimentally test the role of immunosuppressive agents in measles virus therapy, a CEA retargeted measles virus was used to treat a CEA positive murine colon adenocarcinoma implanted in syngeneic C57BL/6 mice.[121] This targeted virus was also armed with the prodrug convertase purine nucleotide phosphorylase (PNP). Systemic delivery of MV-PNPanti CEA had no substantial oncolytic activity, but in combination with the prodrug, 6methyl purine-2'-deoxyroboside, it was therapeutic, revealing synergistic affects between virus and prodrug. Immunosuppression with cyclophosphamide was shown to retard the appearance of measles neutralizing antibodies and also to enhance oncolytic efficacy. 


\section{Current Status and Future Prospects}

Measles virotherapy has recently emerged as a safe and highly promising experimental approach to the treatment of human cancer. Clinical testing is still at an early stage and it remains possible that efficacy will be limited by preexisting anti-measles immunity. However, ongoing research emphasizing the use of engineered viruses, infected cell carriers, and supplemental therapy within immunosuppressive drugs is already offering viable strategies to enhance the potency of these agents, even in the face of preexisting antimeasles immunity.

\section{Acknowledgments}

Dr. Stephen Russell and Dr. Kah-Whye Peng are supported by funds from the NIH/NCI (CA100634 and CA129966 to Dr. Stephen Russell and CA118488 to Dr. Kah-Whye Peng). A grant from the Rapid Access to Intervention Development (RAID) Program of the NCI supported the manufacture of MV-NIS and toxicology studies in transgenic mice and squirrel monkeys. Efforts of numerous individuals including clinical collaborators (Drs. Evanthia Galanis, Angela Dispenzieri, Lynn C Hartmann, David Dingli), members of the virus manufacturing facility (Drs. Mark Federspiel and Linda Gregory, Guy Griesmann, Kirsten Langfield, Julie Sauer, Sharon Stephan, Henry Walker, Troy Wegman, Cindy Whitcomb) and members of the pharmacology/toxicology group (Rae Myers, Suzanne Greiner, Mary Harvey, Pam Ryno, Nathan Jenks, Emily Mader) are gratefully acknowledged.

\section{Bibliography}

1. Aghi M, Martuza RL. Oncolytic viral therapies - the clinical experience. Oncogene. 2005; 24(52): 7802-7816. [PubMed: 16299539]

2. Hermiston T. A demand for next-generation oncolytic adenoviruses. Curr Opin Mol Ther. 2006; 8(4):322-330. [PubMed: 16955695]

3. Liu TC, Galanis E, Kirn D. Clinical trial results with oncolytic virotherapy: a century of promise, a decade of progress. Nat Clin Pract Oncol. 2007; 4(2):101-117. [PubMed: 17259931]

4. Tai CK, Kasahara N. Replication-competent retrovirus vectors for cancer gene therapy. Front Biosci. 2008; 13:3083-3095. [PubMed: 17981778]

5. Kelly E, Russell SJ. History of oncolytic viruses: genesis to genetic engineering. Mol Ther. 2007; 15(4):651-659. [PubMed: 17299401]

6. Sinkovics JG, Horvath JC. Newcastle disease virus (NDV): brief history of its oncolytic strains. J Clin Virol. 2000; 16(1):1-15. [PubMed: 10680736]

7. Bluming A, Ziegler J. Regression of Burkitt's lymphoma in association with measles infection. The Lancet. 1971 Jul 10.:105-106.

8. Zygiert Z. Hodgkin's disease: remissions after measles. Lancet. 1971; 1(7699):593. [PubMed: 4100922]

9. Hoster HA, Zanes RP Jr, Haam EVon. Studies in Hodgkin's syndrome; the association of viral hepatitis and Hodgkin's disease; a preliminary report. Cancer Res. 1949; 9(8):473-480. [PubMed: 18134519]

10. Shimizu Y, et al. Immunotherapy of advanced gynecologic cancer patients utilizing mumps virus. Cancer Detect Prev. 1988; 12(1-6):487-495. [PubMed: 2972361]

11. Asada T. Treatment of human cancer with mumps virus. Cancer. 1974; 34(6):1907-1928. [PubMed: 4611607]

12. Okuno Y, et al. Studies on the use of mumps virus for treatment of human cancer. Biken J. 1978; 21(2):37-49. [PubMed: 749908]

13. Newman W, Southam CM. Virus treatment in advanced cancer; a pathological study of fifty-seven cases. Cancer. 1954; 7(1):106-118. [PubMed: 13126905]

14. Southam CM, Moore AE. Clinical studies of viruses as antineoplastic agents with particular reference to Egypt 101 virus. Cancer. 1952; 5(5):1025-1034. [PubMed: 12988191]

15. Huebner RJ, et al. Studies on the use of viruses in the treatment of carcinoma of the cervix. Cancer. 1956; 9(6):1211-1218. [PubMed: 13383455] 
16. Russell SJ, Peng KW. Viruses as anticancer drugs. Trends Pharmacol Sci. 2007; 28(7):326-333. [PubMed: 17573126]

17. Campbell SA, Gromeier M. Oncolytic viruses for cancer therapy I. Cell-external factors: virus entry and receptor interaction. Onkologie. 2005; 28(3):144-149. [PubMed: 15772465]

18. Campbell SA, Gromeier M. Oncolytic viruses for cancer therapy II. Cell-internal factors for conditional growth in neoplastic cells. Onkologie. 2005; 28(4):209-215. [PubMed: 15840970]

19. Lichty BD, et al. Vesicular stomatitis virus: re-inventing the bullet. Trends Mol Med. 2004; 10(5): 210-216. [PubMed: 15121047]

20. Lorence RM, et al. Phase 1 clinical experience using intravenous administration of PV701, an oncolytic Newcastle disease virus. Curr Cancer Drug Targets. 2007; 7(2):157-167. [PubMed: 17346107]

21. Thorne $\mathrm{SH}$, et al. Rational strain selection and engineering creates a broad-spectrum, systemically effective oncolytic poxvirus, JX-963. J Clin Invest. 2007; 117(11):3350-3358. [PubMed: 17965776]

22. Forsyth $\mathrm{P}$, et al. A phase I trial of intratumoral administration of reovirus in patients with histologically confirmed recurrent malignant gliomas. Mol Ther. 2008; 16(3):627-632. [PubMed: 18253152]

23. Yu W, Fang H. Clinical trials with oncolytic adenovirus in China. Curr Cancer Drug Targets. 2007; 7(2):141-148. [PubMed: 17346105]

24. Shen Y, Nemunaitis J. Herpes simplex virus 1 (HSV-1) for cancer treatment. Cancer Gene Ther. 2006; 13(11):975-992. [PubMed: 16604059]

25. Kinoh H, Inoue M. New cancer therapy using genetically-engineered oncolytic Sendai virus vector. Front Biosci. 2008; 13:2327-2334. [PubMed: 17981715]

26. Nakamura T, Russell SJ. Oncolytic measles viruses for cancer therapy. Expert Opin Biol Ther. 2004; 4(10):1685-1692. [PubMed: 15461580]

27. Russell S. Replicating vectors for cancer therapy: A question of strategy. Seminars in Cancer Biology. 1994; 5:437-443. [PubMed: 7703443]

28. Russell SJ. Replicating vectors for cancer therapy: a question of strategy. Semin Cancer Biol. 1994; 5(6):437-443. [PubMed: 7703443]

29. Griffin, D. Measles Virus. In: Griffin, D., et al., editors. Field's Virology. Philadelphia: Lippincott Williams \& Wilkins; 2001. p. 1401

30. Measles pneumonitis following measles-mumps-rubella vaccination of a patient with HIV infection, 1993. MMWR Morb Mortal Wkly Rep. 1996; 45(28):603-606. [PubMed: 8676852]

31. Yanagi Y, et al. Measles virus receptors and tropism. Jpn J Infect Dis. 2006; 59(1):1-5. [PubMed: 16495625]

32. Naniche D, et al. Human membrane cofactor protein (CD46) acts as a cellular receptor for measles virus. J Virol. 1993; 67(10):6025-6032. [PubMed: 8371352]

33. Dorig RE, et al. The human CD46 molecule is a receptor for measles virus (Edmonston strain). Cell. 1993; 75(2):295-305. [PubMed: 8402913]

34. Hsu EC, et al. A single amino acid change in the hemagglutinin protein of measles virus determines its ability to bind CD46 and reveals another receptor on marmoset B cells. J Virol. 1998; 72(4):2905-2916. [PubMed: 9525611]

35. Xie M, et al. Amino acid substitutions at position 481 differently affect the ability of the measles virus hemagglutinin to induce cell fusion in monkey and marmoset cells co-expressing the fusion protein. Arch Virol. 1999; 144(9):1689-1699. [PubMed: 10542019]

36. Rota JS, et al. Comparison of sequences of the H, F, and $\mathrm{N}$ coding genes of measles virus vaccine strains. Virus Res. 1994; 31(3):317-330. [PubMed: 8191786]

37. Nielsen L, et al. Adaptation of wild-type measles virus to CD46 receptor usage. Arch Virol. 2001; 146(2):197-208. [PubMed: 11315632]

38. Riley-Vargas RC, et al. CD46: expanding beyond complement regulation. Trends Immunol. 2004; 25(9):496-503. [PubMed: 15324743]

39. Liszewski MK, Atkinson JP. Membrane cofactor protein. Curr Top Microbiol Immunol. 1992; 178:45-60. [PubMed: 1424776] 
40. Fishelson Z, et al. Obstacles to cancer immunotherapy: expression of membrane complement regulatory proteins (mCRPs) in tumors. Mol Immunol. 2003; 40(2-4):109-123. [PubMed: 12914817]

41. Durrant LG, Spendlove I. Immunization against tumor cell surface complement-regulatory proteins. Curr Opin Investig Drugs. 2001; 2(7):959-966.

42. Hara T, et al. High expression of membrane cofactor protein of complement (CD46) in human leukaemia cell lines: implication of an alternatively spliced form containing the STA domain in CD46 up-regulation. Scand J Immunol. 1995; 42(6):581-590. [PubMed: 8552981]

43. Seya T, et al. Quantitative analysis of membrane cofactor protein (MCP) of complement. High expression of MCP on human leukemia cell lines, which is down-regulated during cell differentiation. J Immunol. 1990; 145(1):238-245. [PubMed: 1694203]

44. Ong HT, et al. Oncolytic measles virus targets high CD46 expression on multiple myeloma cells. Exp Hematol. 2006; 34(6):713-720. [PubMed: 16728275]

45. Bjorge L, et al. Complement-regulatory proteins in ovarian malignancies. Int J Cancer. 1997; 70(1):14-25. [PubMed: 8985085]

46. Varsano $S$, et al. Human lung cancer cell lines express cell membrane complement inhibitory proteins and are extremely resistant to complement-mediated lysis; a comparison with normal human respiratory epithelium in vitro, and an insight into mechanism(s) of resistance. Clin Exp Immunol. 1998; 113(2):173-182. [PubMed: 9717965]

47. Blok VT, et al. A possible role of CD46 for the protection in vivo of human renal tumor cells from complement-mediated damage. Lab Invest. 2000; 80(3):335-344. [PubMed: 10744069]

48. Simpson KL, et al. Expression of the complement regulatory proteins decay accelerating factor (DAF, CD55), membrane cofactor protein (MCP, CD46) and CD59 in the normal human uterine cervix and in premalignant and malignant cervical disease. Am J Pathol. 1997; 151(5):1455-1467. [PubMed: 9358772]

49. Murray KP, et al. Expression of complement regulatory proteins-CD 35, CD 46, CD 55, and CD 59-in benign and malignant endometrial tissue. Gynecol Oncol. 2000; 76(2):176-182. [PubMed: 10637067]

50. Kinugasa N, et al. Expression of membrane cofactor protein (MCP, CD46) in human liver diseases. Br J Cancer. 1999; 80(11):1820-1825. [PubMed: 10468303]

51. Juhl H, et al. Frequent expression of complement resistance factors CD46, CD55, and CD59 on gastrointestinal cancer cells limits the therapeutic potential of monoclonal antibody 17-1A. J Surg Oncol. 1997; 64(3):222-230. [PubMed: 9121154]

52. Gorter A, et al. Expression of CD46, CD55, and CD59 on renal tumor cell lines and their role in preventing complement-mediated tumor cell lysis. Lab Invest. 1996; 74(6):1039-1049. [PubMed: 8667608]

53. Thorsteinsson L, et al. The complement regulatory proteins CD46 and CD59, but not CD55, are highly expressed by glandular epithelium of human breast and colorectal tumour tissues. Apmis. 1998; 106(9):869-878. [PubMed: 9808413]

54. Yamakawa M, et al. Protection of thyroid cancer cells by complement-regulatory factors. Cancer. 1994; 73(11):2808-2817. [PubMed: 7514955]

55. Anderson BD, et al. High CD46 receptor density determines preferential killing of tumor cells by oncolytic measles virus. Cancer Res. 2004; 64(14):4919-4926. [PubMed: 15256464]

56. Balachandran S, Barber GN. PKR in innate immunity, cancer, and viral oncolysis. Methods Mol Biol. 2007; 383:277-301. [PubMed: 18217692]

57. Basler CF, Garcia-Sastre A. Viruses and the type I interferon antiviral system: induction and evasion. Int Rev Immunol. 2002; 21(4-5):305-337. [PubMed: 12486817]

58. Strong JE, et al. The molecular basis of viral oncolysis: usurpation of the Ras signaling pathway by reovirus. Embo J. 1998; 17(12):3351-3362. [PubMed: 9628872]

59. Stojdl DF, et al. VSV strains with defects in their ability to shutdown innate immunity are potent systemic anti-cancer agents. Cancer Cell. 2003; 4(4):263-275. [PubMed: 14585354]

60. Griffin DE, Pan CH, Moss WJ. Measles vaccines. Front Biosci. 2008; 13:1352-1370. [PubMed: 17981635] 
61. McQuillan GM, et al. Seroprevalence of measles antibody in the US population, 1999-2004. J Infect Dis. 2007; 196(10):1459-1464. [PubMed: 18008224]

62. Taqi AM, et al. Regression of Hodgkin's disease after measles. Lancet. 1981; 1(8229):1112. [PubMed: 6112483]

63. Mota HC. Infantile Hodgkin's disease: remission after measles. Br Med J. 1973; 2(5863):421. [PubMed: 4574047]

64. Ziegler JL. Spontaneous remission in Burkitt's lymphoma. Natl Cancer Inst Monogr. 1976; 44:6165. [PubMed: 799761]

65. Nagy N, et al. SH2D1A expression in Burkitt lymphoma cells is restricted to EBV positive group I lines and is downregulated in parallel with immunoblastic transformation. Int J Cancer. 2002; 100(4):433-440. [PubMed: 12115526]

66. Nakamura T, et al. Rescue and propagation of fully retargeted oncolytic measles viruses. Nat Biotechnol. 2005; 23(2):209-214. [PubMed: 15685166]

67. Cocks BG, et al. A novel receptor involved in T-cell activation. Nature. 1995; 376(6537):260-263. [PubMed: 7617038]

68. Enders JF, Peebles TC. Propagation in tissue cultures of cytopathogenic agents from patients with measles. Proc Soc Exp Biol Med. 1954; 86(2):277-286. [PubMed: 13177653]

69. Katz SL. Immunization with Live Attenuated Measles Virus Vaccines: Five Years' Experience. Arch Gesamte Virusforsch. 1965; 16:222-230. [PubMed: 14322868]

70. Katz, S. The history of measles virus and the development and utilization of measles virus vaccines, in Vaccinia, vaccination and vaccinology: Jenner, Pasteur and their successors. Plotkins, S.; Fantini, B., editors. Paris: Elsevier; 1996. p. 265

71. Radecke F, et al. Rescue of measles viruses from cloned DNA. Embo J. 1995; 14(23):5773-5784. [PubMed: 8846771]

72. Grote D, et al. Live attenuated measles virus induces regression of human lymphoma xenografts in immunodeficient mice. Blood. 2001; 97(12):3746-3754. [PubMed: 11389012]

73. Peng KW, et al. Systemic therapy of myeloma xenografts by an attenuated measles virus. Blood. 2001; 98(7):2002-2007. [PubMed: 11567982]

74. Peng KW, et al. Intraperitoneal therapy of ovarian cancer using an engineered measles virus. Cancer Res. 2002; 62(16):4656-4662. [PubMed: 12183422]

75. Phuong LK, et al. Use of a vaccine strain of measles virus genetically engineered to produce carcinoembryonic antigen as a novel therapeutic agent against glioblastoma multiforme. Cancer Res. 2003; 63(10):2462-2469. [PubMed: 12750267]

76. Blechacz B, et al. Engineered measles virus as a novel oncolytic viral therapy system for hepatocellular carcinoma. Hepatology. 2006; 44(6):1465-1477. [PubMed: 17133484]

77. McDonald CJ, et al. A measles virus vaccine strain derivative as a novel oncolytic agent against breast cancer. Breast Cancer Res Treat. 2006; 99(2):177-184. [PubMed: 16642271]

78. Hoffmann D, et al. Synergy between expression of fusogenic membrane proteins, chemotherapy and facultative virotherapy in colorectal cancer. Gene Ther. 2006; 13(21):1534-1544. [PubMed: 16791286]

79. Myers R, et al. Oncolytic activities of approved mumps and measles vaccines for therapy of ovarian cancer. Cancer Gene Ther. 2005; 12(7):593-599. [PubMed: 15746945]

80. Heinzerling L, et al. Oncolytic measles virus in cutaneous T-cell lymphomas mounts antitumor immune responses in vivo and targets interferon-resistant tumor cells. Blood. 2005; 106(7):22872294. [PubMed: 15961518]

81. Peng KW, et al. Non-invasive in vivo monitoring of trackable viruses expressing soluble marker peptides. Nat Med. 2002; 8(5):527-531. [PubMed: 11984600]

82. Peng KW, et al. Pharmacokinetics of oncolytic measles virotherapy: eventual equilibrium between virus and tumor in an ovarian cancer xenograft model. Cancer Gene Ther. 2006; 13(8):732-738. [PubMed: 16543921]

83. Hasegawa K, et al. Dual therapy of ovarian cancer using measles viruses expressing carcinoembryonic antigen and sodium iodide symporter. Clin Cancer Res. 2006; 12(6):1868-1875. [PubMed: 16551872] 
84. Dingli D, et al. Image-guided radiovirotherapy for multiple myeloma using a recombinant measles virus expressing the thyroidal sodium iodide symporter. Blood. 2004; 103(5):1641-1646. [PubMed: 14604966]

85. Dadachova E, Carrasco N. The Na/I symporter (NIS): imaging and therapeutic applications. Semin Nucl Med. 2004; 34(1):23-31. [PubMed: 14735456]

86. Riesco-Eizaguirre G, Santisteban P. A perspective view of sodium iodide symporter research and its clinical implications. Eur J Endocrinol. 2006; 155(4):495-512. [PubMed: 16990649]

87. Mazzaferri EL, Kloos RT. Clinical review 128: Current approaches to primary therapy for papillary and follicular thyroid cancer. J Clin Endocrinol Metab. 2001; 86(4):1447-1463. [PubMed: 11297567]

88. Dingli D, et al. Combined I-124 Positron Emission Tomography/Computed Tomography Imaging of NIS Gene Expression in Animal Models of Stably Transfected and Intravenously Transfected Tumor. Mol Imaging Biol. 2005:1-8.

89. Carlson SK, et al. In vivo quantitation of intratumoral radioisotope uptake using micro-single photon emission computed tomography/computed tomography. Mol Imaging Biol. 2006; 8(6): 324-332. [PubMed: 17053863]

90. Dingli D, et al. Genetically targeted radiotherapy for multiple myeloma. Blood. 2003; 102(2):489_ 496. [PubMed: 12649158]

91. Dingli D, et al. Mathematical modeling of cancer radiovirotherapy. Math Biosci. 2006; 199(1):5578. [PubMed: 16376950]

92. Wein LM, Wu JT, Kirn DH. Validation and analysis of a mathematical model of a replicationcompetent oncolytic virus for cancer treatment: implications for virus design and delivery. Cancer Res. 2003; 63(6):1317-1324. [PubMed: 12649193]

93. Bajzer Z, et al. Modeling of cancer virotherapy with recombinant measles viruses. J Theor Biol. 2008; 252(1):109-122. [PubMed: 18316099]

94. Gotoh B, et al. Paramyxovirus accessory proteins as interferon antagonists. Microbiol Immunol. 2001; 45(12):787-800. [PubMed: 11838896]

95. Palosaari $\mathrm{H}$, et al. STAT protein interference and suppression of cytokine signal transduction by measles virus V protein. J Virol. 2003; 77(13):7635-7644. [PubMed: 12805463]

96. Shaffer JA, Bellini WJ, Rota PA. The C protein of measles virus inhibits the type I interferon response. Virology. 2003; 315(2):389-397. [PubMed: 14585342]

97. Takeuchi K, et al. Measles virus V protein blocks interferon (IFN)-alpha/beta but not IFN-gamma signaling by inhibiting STAT1 and STAT2 phosphorylation. FEBS Lett. 2003; 545(2-3):177-182. [PubMed: 12804771]

98. Devaux P, et al. Tyrosine 110 in the measles virus phosphoprotein is required to block STAT1 phosphorylation. Virology. 2007; 360(1):72-83. [PubMed: 17112561]

99. Ohno $\mathrm{S}$, et al. Dissection of measles virus V protein in relation to its ability to block alpha/beta interferon signal transduction. J Gen Virol. 2004; 85(Pt 10):2991-2999. [PubMed: 15448362]

100. Naniche D, et al. Evasion of host defenses by measles virus: wild-type measles virus infection interferes with induction of Alpha/Beta interferon production. J Virol. 2000; 74(16):7478-7484. [PubMed: 10906201]

101. Stojdl DF, et al. Exploiting tumor-specific defects in the interferon pathway with a previously unknown oncolytic virus. Nat Med. 2000; 6(7):821-825. [PubMed: 10888934]

102. Haralambieva I, et al. Engineering oncolytic measles virus to circumvent the intracellular innate immune response. Mol Ther. 2007; 15(3):588-597. [PubMed: 17245355]

103. Bankamp B, et al. Genetic changes that affect the virulence of measles virus in a rhesus macaque model. Virology. 2008; 373(1):39-50. [PubMed: 18155263]

104. Waehler R, Russell SJ, Curiel DT. Engineering targeted viral vectors for gene therapy. Nat Rev Genet. 2007; 8(8):573-587. [PubMed: 17607305]

105. Schneider U, et al. Recombinant measles viruses efficiently entering cells through targeted receptors. J Virol. 2000; 74(21):9928-9936. [PubMed: 11024120] 
106. Hammond AL, et al. Single-chain antibody displayed on a recombinant measles virus confers entry through the tumor-associated carcinoembryonic antigen. J Virol. 2001; 75(5):2087-2096. [PubMed: 11160713]

107. Peng KW, et al. Oncolytic measles viruses displaying a single-chain antibody against CD38, a myeloma cell marker. Blood. 2003; 101(7):2557-2562. [PubMed: 12433686]

108. Bucheit AD, et al. An oncolytic measles virus engineered to enter cells through the CD20 antigen. Mol Ther. 2003; 7(1):62-72. [PubMed: 12573619]

109. Peng K-W, et al. Targeting membrane fusion to specific peptide/MHC complexes through a highaffinity T-cell receptor. Gene Ther. 2004; 11(15):1234-1239. [PubMed: 15215883]

110. Hallak LK, et al. Targeted measles virus vector displaying echistatin infects endothelial cells via alpha(v)beta3 and leads to tumor regression. Cancer Res. 2005; 65(12):5292-5300. [PubMed: 15958576]

111. Vongpunsawad S, et al. Selectively receptor-blind measles viruses: Identification of residues necessary for SLAM- or CD46-induced fusion and their localization on a new hemagglutinin structural model. J Virol. 2004; 78(1):302-313. [PubMed: 14671112]

112. Nakamura T, et al. Antibody-targeted cell fusion. Nat Biotechnol. 2004; 22(3):331-336. [PubMed: 14990955]

113. Lecouturier V, et al. Identification of two amino acids in the hemagglutinin glycoprotein of measles virus (MV) that govern hemadsorption, HeLa cell fusion, and CD46 downregulation: phenotypic markers that differentiate vaccine and wild-type MV strains. J Virol. 1996; 70(7): 4200-4204. [PubMed: 8676439]

114. Hadac EM, et al. Reengineering paramyxovirus tropism. Virology. 2004; 329(2):217-225. [PubMed: 15518802]

115. Kaufmann M, et al. Crystal structure of the anti-His tag antibody 3D5 single-chain fragment complexed to its antigen. J Mol Biol. 2002; 318(1):135-147. [PubMed: 12054774]

116. Hasegawa $\mathrm{K}$, et al. The use of a tropism-modified measles virus in folate receptor-targeted virotherapy of ovarian cancer. Clin Cancer Res. 2006; 12(20 Pt 1):6170-6178. [PubMed: 17062694]

117. Hasegawa $\mathrm{K}$, et al. Affinity thresholds for membrane fusion triggering by viral glycoproteins. $\mathrm{J}$ Virol. 2007; 81(23):13149-13157. [PubMed: 17804513]

118. Ungerechts G, et al. Lymphoma chemovirotherapy: CD20-targeted and convertase-armed measles virus can synergize with fludarabine. Cancer Res. 2007; 67(22):10939-10947. [PubMed: 18006839]

119. Paraskevakou G, et al. Epidermal growth factor receptor (EGFR)-retargeted measles virus strains effectively target EGFR- or EGFRvIII expressing gliomas. Mol Ther. 2007; 15(4):677-686. [PubMed: 17299404]

120. Allen C, et al. Retargeted oncolytic measles strains entering via the EGFRvIII receptor maintain significant antitumor activity against gliomas with increased tumor specificity. Cancer Res. 2006; 66(24):11840-11850. [PubMed: 17178881]

121. Ungerechts G, et al. An immunocompetent murine model for oncolysis with an armed and targeted measles virus. Mol Ther. 2007; 15(11):1991-1997. [PubMed: 17712331]

122. Mrkic B, et al. Measles virus spread and pathogenesis in genetically modified mice. Journal of Virology. 1998; 72(9):7420-7427. [PubMed: 9696838]

123. Oldstone MB, et al. Measles virus infection in a transgenic model: virus-induced immunosuppression and central nervous system disease. Cell. 1999; 98(5):629-640. [PubMed: 10490102]

124. Manchester M, Rall GF. Model Systems: transgenic mouse models for measles pathogenesis. Trends Microbiol. 2001; 9(1):19-23. [PubMed: 11166238]

125. Mrkic B, et al. Lymphatic dissemination and comparative pathology of recombinant measles viruses in genetically modified mice. J Virol. 2000; 74(3):1364-1372. [PubMed: 10627547]

126. Kemper C, et al. Membrane cofactor protein (MCP; CD46) expression in transgenic mice. Clin Exp Immunol. 2001; 124(2):180-189. [PubMed: 11422193] 
127. Peng KW, et al. Biodistribution of oncolytic measles virus after intraperitoneal administration into Ifnar-CD46Ge transgenic mice. Hum Gene Ther. 2003; 14(16):1565-1577. [PubMed: 14577918]

128. Kobune F, et al. Nonhuman primate models of measles. Lab Anim Sci. 1996; 46(3):315-320. [PubMed: 8799939]

129. van Binnendijk RS, et al. Viral replication and development of specific immunity in macaques after infection with different measles virus strains. J Infect Dis. 1994; 170(2):443-448. [PubMed: 8035034]

130. Auwaerter PG, et al. Measles virus infection in rhesus macaques: altered immune responses and comparison of the virulence of six different virus strains. J Infect Dis. 1999; 180(4):950-958. [PubMed: 10479117]

131. Takeda M, et al. Measles virus attenuation associated with transcriptional impediment and a few amino acid changes in the polymerase and accessory proteins. J Virol. 1998; 72(11):8690-8696. [PubMed: 9765410]

132. Kobune F, Sakata H, Sugiura A. Marmoset lymphoblastoid cells as a sensitive host for isolation of measles virus. J Virol. 1990; 64(2):700-705. [PubMed: 2153236]

133. Aldous IR, et al. Vaccination aginst measles. III. Clinical trial in British children. Br Med J. 1961; 2(5262):1250-1253. [PubMed: 13860216]

134. Collard P, et al. Vaccination against measles. II. Clinical trial in Nigerian children. Br Med J. 1961; 2(5262):1246-1250. [PubMed: 13880515]

135. Katz SL, et al. Studies on an attenuated measles-virus vaccine. VIII. General summary and evaluation of the results of vaccine. N Engl J Med. 1960; 263:180-184. [PubMed: 14404830]

136. Schwarz AJ, et al. Experimental vaccination against measles. I. Tests of live measles and distemper vaccine in monkeys and two human volunteers under laboratory conditions. J Am Med Assoc. 1960; 173:861-867. [PubMed: 14444038]

137. Enders JF, et al. Studies on an attenuated measles-virus vaccine. I. Development and preparations of the vaccine: technics for assay of effects of vaccination. N Engl J Med. 1960; 263:153-159. [PubMed: 13820246]

138. Goffe AP, Laurence GD. Vaccination against measles. I. Preparation and testing of vaccines consisting of living attenuated virus. Br Med J. 1961; 2(5262):1244-1246. [PubMed: 13899545]

139. Hsu EC, et al. Artificial mutations and natural variations in the CD46 molecules from human and monkey cells define regions important for measles virus binding. J Virol. 1997; 71(8):61446154. [PubMed: 9223509]

140. Peng KW, et al. Organ distribution of gene expression after intravenous infusion of targeted and untargeted lentiviral vectors. Gene Ther. 2001; 8(19):1456-1463. [PubMed: 11593358]

141. Allen C, et al. Oncolytic measles virus strains in the treatment of gliomas. Expert Opin Biol Ther. 2008; 8(2):213-220. [PubMed: 18194077]

142. Myers RM, et al. Preclinical pharmacology and toxicology of intravenous MV-NIS, an oncolytic measles virus administered with or without cyclophosphamide. Clin Pharmacol Ther. 2007; 82(6):700-710. [PubMed: 17971816]

143. Wang Y, Yuan F. Delivery of viral vectors to tumor cells: extracellular transport, systemic distribution, and strategies for improvement. Ann Biomed Eng. 2006; 34(1):114-127. [PubMed: 16520902]

144. Fisher K. Striking out at disseminated metastases: the systemic delivery of oncolytic viruses. Curr Opin Mol Ther. 2006; 8(4):301-313. [PubMed: 16955693]

145. Scallan CD, et al. Human immunoglobulin inhibits liver transduction by AAV vectors at low AAV2 neutralizing titers in SCID mice. Blood. 2006; 107(5):1810-1817. [PubMed: 16249376]

146. Klasse PJ, Sattentau QJ. Occupancy and mechanism in antibody-mediated neutralization of animal viruses. J Gen Virol. 2002; 83(Pt 9):2091-2108. [PubMed: 12185262]

147. Reid T, et al. Hepatic arterial infusion of a replication-selective oncolytic adenovirus (d11520): phase II viral, immunologic, and clinical endpoints. Cancer Res. 2002; 62(21):6070-6079. [PubMed: 12414631]

148. Hangartner L, Zinkernagel RM, Hengartner H. Antiviral antibody responses: the two extremes of a wide spectrum. Nat Rev Immunol. 2006; 6(3):231-243. [PubMed: 16498452] 
149. Audet S, et al. Measles-virus-neutralizing antibodies in intravenous immunoglobulins. J Infect Dis. 2006; 194(6):781-789. [PubMed: 16941344]

150. Dingli D, et al. Interaction of measles virus vectors with Auger electron emitting radioisotopes. Biochem Biophys Res Commun. 2005; 337(1):22-29. [PubMed: 16171777]

151. Jacobson DR, Zolla-Pazner S. Immunosuppression and infection in multiple myeloma. Semin Oncol. 1986; 13(3):282-290. [PubMed: 3532328]

152. Zingher A, Mortimer P. Convalescent whole blood, plasma and serum in the prophylaxis of measles: JAMA, 12 April, 1926; 1180-1187. Rev Med Virol. 2005; 15(6):407-418. discussion 418-21. [PubMed: 16211552]

153. Ordman CW, Jennings CG, Janeway CA, Chemical Clinical. and Immunological Studies on the Products of Human Plasma Fractionation. Xii. The Use of Concentrated Normal Human Serum Gamma Globulin (Human Immune Serum Globulin) in the Prevention and Attenuation of Measles. J Clin Invest. 1944; 23(4):541-549. [PubMed: 16695130]

154. Osunkoya BO, et al. Evidence that circulating lymphocytes act as vehicles or viraemia in measles. West Afr J Med. 1990; 9(1):35-39. [PubMed: 2271420]

155. Munguia A, et al. Cell carriers to deliver oncolytic viruses to sites of myeloma tumor growth. Gene Ther. 2008

156. Iankov ID, et al. Infected cell carriers: a new strategy for systemic delivery of oncolytic measles viruses in cancer virotherapy. Mol Ther. 2007; 15(1):114-122. [PubMed: 17164782]

157. Ong HT, et al. Evaluation of T cells as carriers for systemic measles virotherapy in the presence of antiviral antibodies. Gene Ther. 2007; 14(4):324-333. [PubMed: 17051248]

158. Steinberg, A. Cyclophosphamide. In: Austen, K., et al., editors. Therapeutic Immunology. Malden: Blackwell Science, Inc.; 2001. p. 31-50.

159. Hill, DL. Pharmacology. In: Thomas, CC., editor. A review of cyclophosphamide. Springfield; 1975. p. 60-85.

160. Aisenberg AC, Davis C. The thymus and recovery from cyclophosphamide-induced tolerance to sheep erythrocytes. J Exp Med. 1968; 128(1):35-46. [PubMed: 4173679] 
A

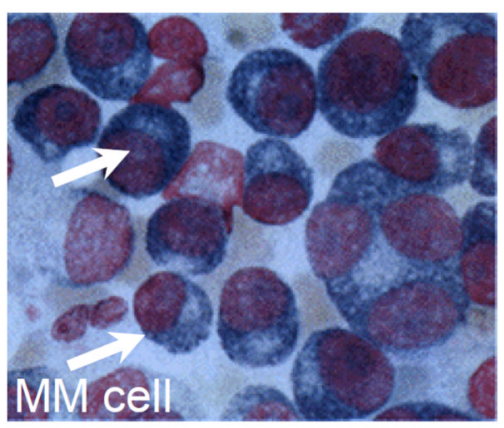

B

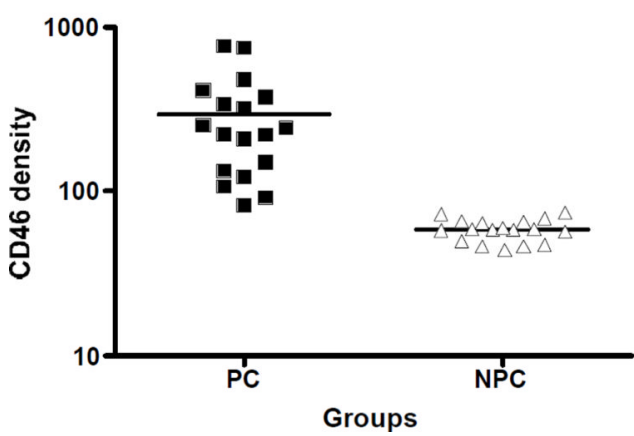

C

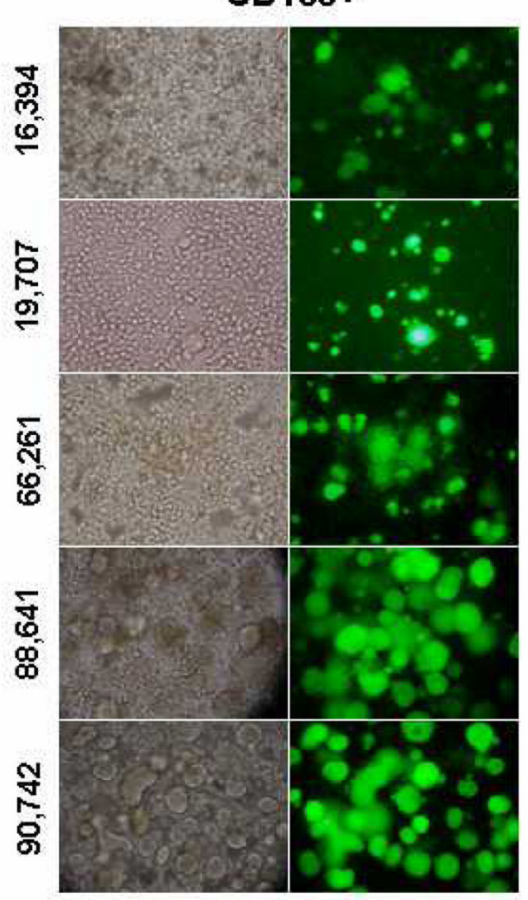

CD138-

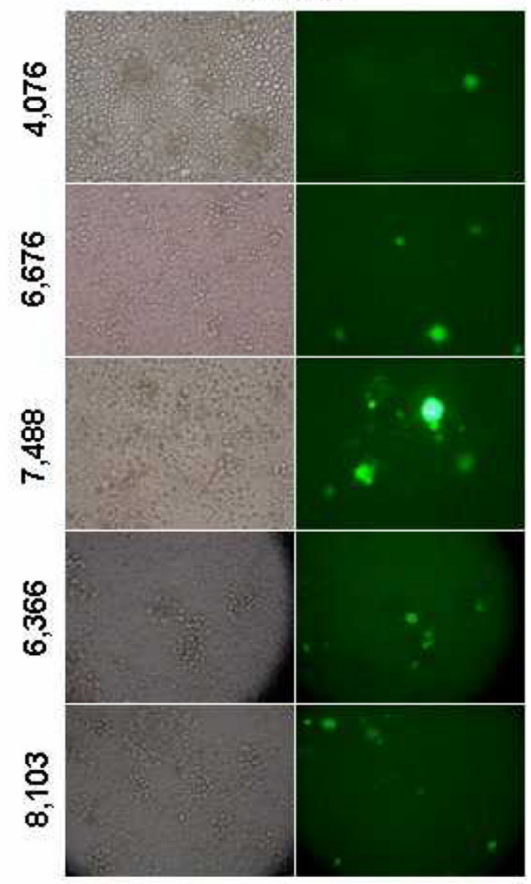

Figure 1.

Attenutated measles virus preferentially targets CD46 which is overexpressed on cancer cells, including multiple myeloma cells. (A) Cytospin of a bone marrow aspirate showing myeloma cells. (B) Bone marrow aspirates obtained from myeloma patients were separated into plasma cells (myeloma) and non-plasma cells (all normal hemapoietic cells in the marrow). Cells were stained with an anti-CD46 antibody and the numbers of CD46 receptors/cell were determined using BD-QuantiBrite Beads.[44] Primary myeloma cells express 7-fold higher CD46 receptors than normal non-plasma cells in the bone marrow. (C) Primary myeloma cells expressing high levels of CD46 receptors (shown on the left) are more susceptible to the cytopathic effects of measles induced syncytial formation compared to normal bone marrow cells isolated from the same bone marrow aspirates [44]. 


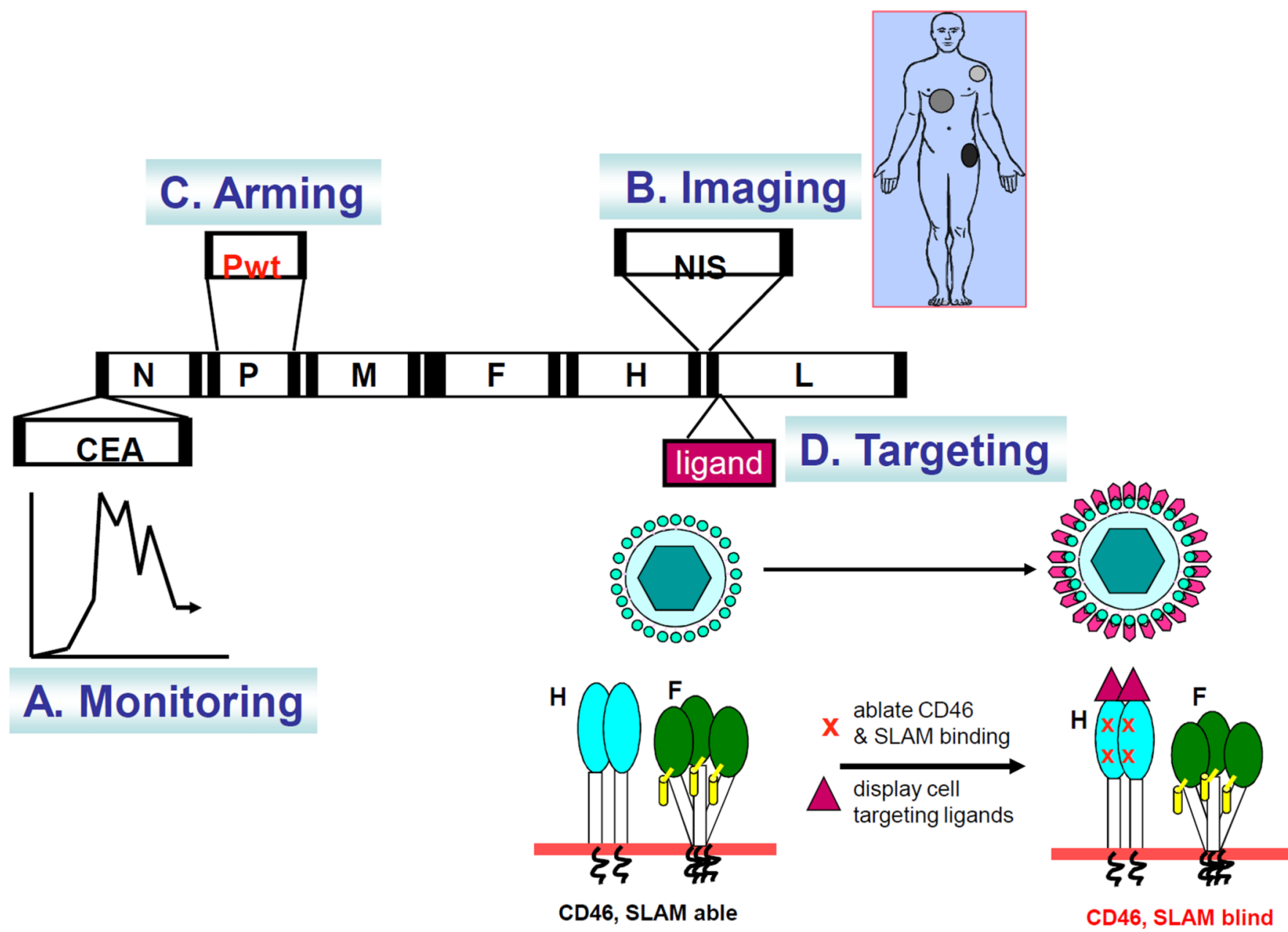

Figure 2.

Genetic engineering of attenuated measles virus for cancer therapy. (A) The virus can be engineered to express soluble marker proteins (eg. MV-CEA) which are secreted into the circulation, thus enabling noninvasive monitoring of the profiles of viral gene expression over time by sampling body fluids[81]. (B) The virus can be engineered to express the sodium iodide symporter (MV-NIS) which concentrates radioiodine in the infected cell, thus enabling noninvasive monitoring of the sites of MV infection by gamma camera, SPECTCT or PET-CT imaging.[84] Virotherapy can also be enhanced by a timely dose of betaemitting I-131 to result in synergistic killing of MV infected tumors. (C) Arming of the virus with genes (e.g. P-gene from wild-type measles) that enable the virus to combat the innate antiviral immunity [102]. (D) Targeting virus entry, the $\mathrm{H}$ glycoprotein of measles virus can accommodate addition of large polypeptides (eg. Single-chain antibodies) as C-terminal extensions on the $\mathrm{H}$ protein. Mutations in the $\mathrm{H}$ protein that ablate fusion via CD46 and SLAM have been identified and incorporated in the retargeted viruses. The displayed ligand redirects binding of the virus to the new receptor to mediate virus entry and syncytial formation via the targeted receptor.[66] 


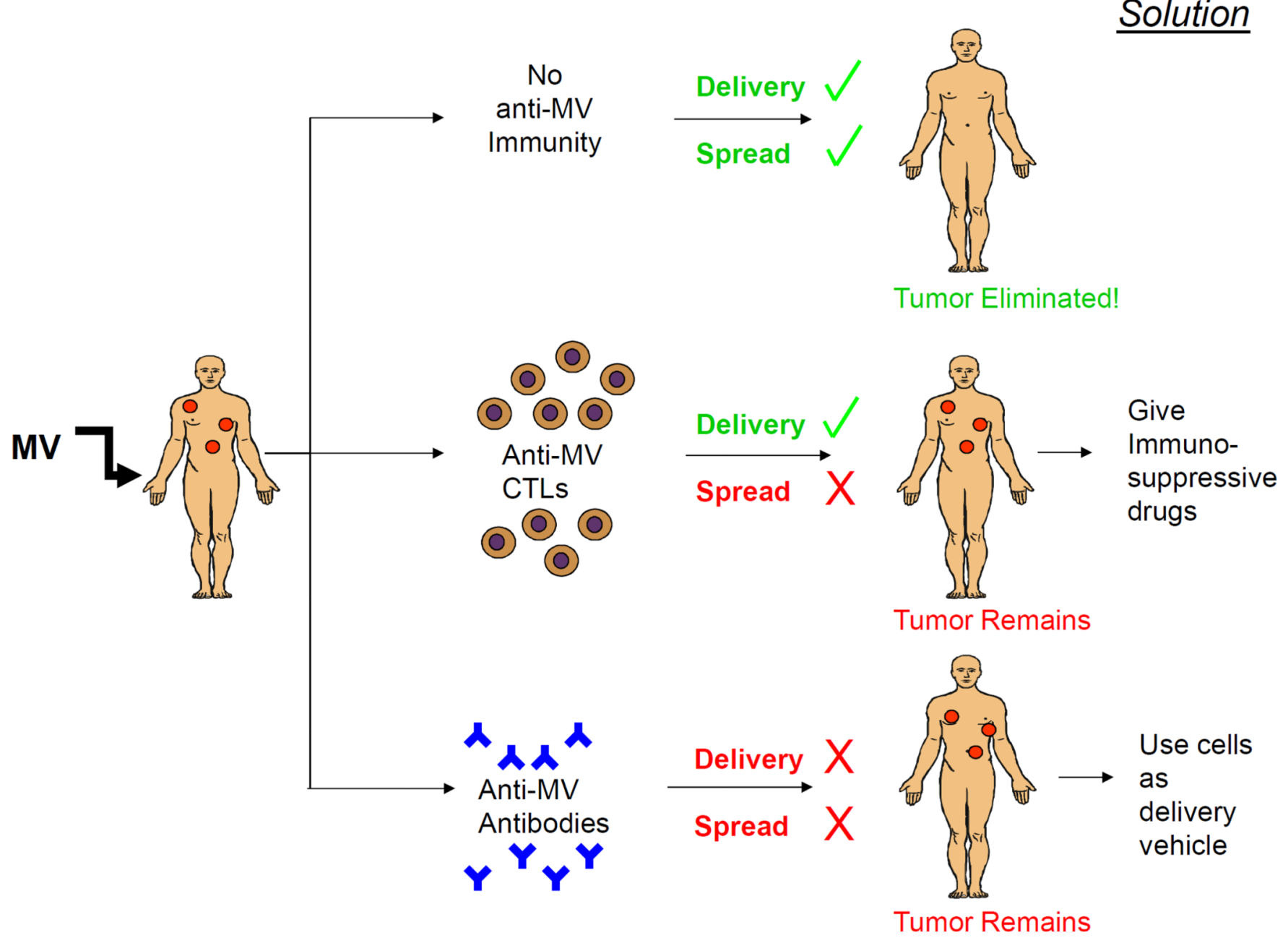

Figure 3.

Considerations for future improvements of measles virotherapy. Ideally, intravascularly administered viruses will reach the tumor sites to result in infection of tumor cells, viral spread and elimination of the tumors. However, anti-measles antibodies can potentially inhibit delivery of the viruses and viral spread in the infected tumor can be inhibited by cell mediated immunity. To combat these barriers to successful therapy, virus infected cell carriers can be exploited to act as Trojan horses to deliver virus to the tumor sites and cell mediated immunity can be controlled by judicious use of immunosuppressive agents such as cyclophosphamide. 